Revista Iberoamericana. Vol. LXIV, Núms. 184-185, Julio-Diciembre 1998; 397-411

\title{
EL 98 EN LA LLEGADA DE JOSÉ LUIS GONZÁLEZ: LAS TRAMPAS DE LA HISTORIA
}

\author{
POR \\ GUILleRMo B. IRIZARRY \\ Bucknell University
}

En este artículo discutiremos la ficcionalización de la invasión estadounidense de Puerto Rico en el verano del 1898 en La llegada: Crónica con ficción (1980), novela del escritor puertorriqueño José Luis González (1926-1996), para proponer que el texto emplaza al paradigma idealista y positivista de la historiografia de los treinta en la isla, lo que el autor llama "el discurso independentista tradicional", ${ }^{1}$ y propone una visión contrahegemónica que otorga un papel protagónico a la base popular. El cuestionamiento epistemológico sugiere la desarticulación de un aparato ideológico de profunda raigambre hispanófila y de afecto desdeñoso hacia la base cultural y étnica. El fenómeno no se puede reducir al historicismo del 98 en Puerto Rico, sin embargo este año sirve de articulación inicial y final de los poderes imperiales en Hispanoamérica y punto de entrada al estudio de lo que fue el golpe de gracia a la separación legal de las últimas colonias españolas en América. La separación discursiva de "lo latinoamericano" y "lo español" se percibe como un punto de fuga ante el cual se reconocen las independencias imaginarias de las culturas nacionales hispanoamericanas.

La llegada: Crónica con "ficción" es de particular interés para entender el valor semántico del 1898, porque se dedica a un "intersticio" en la historia de Puerto Rico que redefinió la división del poder en la isla, la dinámica entre grupos, y los conceptos de cultura y de nación que interpretaba la experiencia colectiva. Como apunta Bhabha

\footnotetext{
'En el ensayo"El país de cuatro pisos"(1978), González explicita su emplazamiento de la historiografía hegemónico-dominante en Puerto Rico. El término "discurso independentista tradicional" se refiere al discurso de corte nacionalista separatista, propulsado, según el autor, por los descendientes de la clase criolla puertorriqueña y reproducida por el Partido Nacionalista, Pedro Albizu Campos y demás simpatizantes del independentismo en Puerto Rico. Es la versión historicista del criollismo literario. No debe confundirse con los sectores del separatismo puertorriqueño afiliados a posturas de corte marxista. González, al establecer estos linajes ideológicos, no sospechaba que dicha "versión de los hechos" habría de intercalarse a la retórica estadoista como apéndice extraño de la "estadidad jíbara". Por lo mismo, en el estudio que nos ocupa, las referencias a los independentistas tradicionales denotan una postura ideológica empleada, desde los treinta, por separatistas, no marxistas, aunque dicha postura llegase a estar a gusto dentro de la retórica hegemónico-dominante, por efecto del aparato discursivo del Partido Popular Democrático y luego del Partido Nuevo Progresista, para la década de los noventa.
} 
It is in the interstices - the overlap and displacement of domains of difference- that the intersubjective and collective experiences of nationness, community interest, or cultural value are negotiated. [...] Terms of cultural engagement, whether antagonistic or affiliative, are produced performatively. The representation of difference must not be read as the reflection of pre-given ethnic or cultural traits set in the fixed tablet of tradition. The social articulation of difference, from the minority perspective, is a complex, on-going negotiation that seeks to authorize cultural hybridities that emerge in moments of historical transformation (2).

A pesar de la representación del momento intersticial, el historicismo de La llegada desdeña el cambio, obsesión de la historiografía idealista, y se ocupa más de la estructura, por lo cual accede al terreno de lo etnográfico. ${ }^{2}$ En este espacio discursivo, lo sincrónico rige ante lo diacrónico, lo extraoficial ante lo oficial, lo vivido ante lo archivístico, y lo subalterno ante lo dominante. Este gesto historiográfico resulta idóneo para presentar las relaciones entre grupos raciales y sociales, el estilo de funcionamiento dentro de los medios de producción y la consolidación de un orden simbólico.

La coyuntura que se utiliza es el desembarco de un contingente de 25.000 soldados estadounidenses en la bahía de Guánica, en el sur de Puerto Rico, el 25 de julio del 1898, bajo el mando del general Nelson Miles. ${ }^{3}$ La historiografía de la primera mitad del siglo XX ha comentado la invasión como una interrupción del "progreso" de la isla hacia la independencia. La novela tiene que entenderse como una propuesta contrahegemónica que busca desmentir la interpretación diseminada por el "discurso independentista tradicional".

Antonio S. Pedreira, autor del canónico Insularismo (1934), es uno de los articuladores y difusores principales de la retórica independentista tradicional a que se refiere González. La visión historicista de Pedreira se infiere de la siguiente cita:

Yo veo tres momentos supremos en el desarrollo de nuestro pueblo: el primero, de formación y acumulación pasiva ... el segundo, de despertar e iniciación, que [...] cierra con la guerra hispanoamericana y el tercero, de indecisión y transición. [...] No me interesa

\footnotetext{
${ }^{2}$ Dado que el texto que nos ocupa es una obra de ficción, no sugiero que La llegada sea una etnografía. Las técnicas de contar la historia presentan estrategias afines a las del etnógrafo, quien desea presentar un pasado de manera sincrónica, mientras que la historiografía tradicional está más interesada en el plano diacrónico. Según James Clifford "The distinction between historical and ethnographic practices depends on that between literate and oral modes of knowledge. History is thought to rest on past - documentary, archival - selections of texts. Etnography is based on present —oral, experiential, observational- evidence [...] it resonates with the established (some would say metaphysical) dichotomy of oral and literate worlds as well as with the pervasive habit in the West of sharply distinguishing synchronic from diachronic, structure from change" (340-41).

${ }^{3}$ La invasión fue la escalación lógica de las hostilidades para extraer de manera definitiva el control imperial español en América. "Desde el comienzo de la guerra, al gobierno de Estados Unidos interesaba ponerle fin al dominio español que quedaba en América. Para lograr este objetivo el presidente McKinley se comprometió públicamente a respaldar la independencia de Cuba y la anexión de Puerto Rico a los Estados Unidos. Al empezar la guerra una escuadra norteamericana bloqueó a Puerto Rico para impedirle que pudiera importar armas y alimentos. Luego, en la noche del 9 de mayo de 1898 el almirante Sampson ordenó el bombardeo de San Juan, causando algunas muertes y muchos destrozos" (Picó 185).
} 
[...] discutir el resultado de este último injerto sino señalar la discontinuidad de nuestra intima evolución, que no llegó a madurar plenamente. [...] Salimos de una transplantación y nos metimos en otra sin acabar de diseñar nuestro ademán, que no hemos perdido por completo, pero que se encuentra transeúnte en el momento histórico en que vivimos ( 25 , énfasis mio).

Para Pedreira, a la altura de los años treita, la invasión provocó un hiato en el "progreso histórico" de Puerto Rico. ${ }^{4}$ Para el crítico, la identidad de Puerto Rico estaba ligada a un paradigma que equipara cultura e "intensidad vital" (24).

Esta explicación de la identidad puertorriqueña está ligada, mayormente, a un discurso que justifica la superioridad de una clase y una raza sobre otras. El análisis del "espíritu" puertorriqueño tiene un componente que incluye la superioridad de las élites blancas sobre los negros y los blancos pobres (éstos porque se habían mezclado con los negros) ${ }^{5}$ Se desprende de esta perspectiva que Pedreira se refiere a la "desorientación" histórica de la clase criolla de Puerto Rico y no a todos los miembros de la nación. ${ }^{6}$ Esta interpretación, extraída directamente de Insularismo — texto canónico puertorriqueño y ejemplo de lo que Gonzálezllamaría el discurso independentista tradicional-, muestra algunas características de una visión de la historia de Puerto Rico que es elitista por naturaleza, y que está afiliada a los intereses de los descendientes de la clase propietaria del país.

Junto con Pedreira podríamos agrupar a otros como Tomás Blanco, autor del Prontuario histórico de Puerto Rico (1935), y a Pedro Albizu Campos, líder del Partido Nacionalista, entre otros, cuya retórica reproduce una ideología criollizante, elitista, de corte positivista, que ensalza el momento colonial español e idealiza la clase criolla propietaria como defensores de los valores patrios. Dentro de dicha retórica, el noventa y ocho es año trágico donde la hegemonía aparente de la clase criolla se pierde y, por ende, el proyecto de independencia para la isla se deshace.

\footnotetext{
${ }^{4}$ El argumento de Pedreira hace referencia a la identidad de Puerto Rico como un organismo cuyo desarrollo natural ha sido alterado por un injerto. Las palabras injerto, evolución y transplantación apuntalan su analogía biológica y su base epistemológica positivista. Hay que señalar su referencia al libro La decadencia de occidente de Oswald Spengler. "Para definir sin grandes errores ese ritmo cósmico del problema y señalar en él la sintaxis de la capacidad puertorriqueña no hay que perder de vista esas zonas de cualidad cuantitativa en que suele dividirse la cultura: universal, nacional e individual. Oswald Spengler [...] divide la primera en dos grandes estadios: la cultura antigua de alma apolínea y la occidental de alma fáustica. [...] Dentro de estos términos tan amplios, España no es más que una actitud en la escala de la cultura occidental, y nosotros un gesto americano de la cultura de España" (24).

${ }^{5}$ Pedreira acredita la superioridad moral de las clases altas blancas a su pureza racial. Los blancos pobres, por otro lado, "no mantuvieron escrupulosamente su nivelación social y poco a poco fueron mezclándose con la raza negra" (28).

${ }^{6}$ Para Pedreira: "La raza blanca era legislativa, la negra ejecutiva; una imponía el proyecto y ordenaba; la otra ofrecía el brazo y obedecía; mientras la europea era dueña de vidas y haciendas, la africana no podía disponer ni siquiera de sus sentires. Tampoco tenía que preocuparse por nada, ni pensar en cosa alguna, ya que la raza mandataria se ocupaba de pensar por todos, conservando de esta manera su fuerza sobre el conjunto" (28).
} 
En su polémico ensayo "El país de cuatro pisos"(1978), González ataca la retórica independentista por minimizar, según él, el sufrimiento del pueblo, mientras hace de las élites mártires de la independencia. La llegada dramatiza sus problemas con este discurso culturalista y ofrece una visión alternativa de la historia que se enfoca en las razones por las cuales los Estados Unidos se adueñaron de la isla con facilidad. En esta evaluación de la invasión, implícita en La llegada, González rechaza las interpretaciones tradicionales de la historia para ofrecer una versión más preocupada con los sectores populares de la isla, con las dinámicas del poder internas y externas, y las repercusiones de esta reestructuración geopolítica a fines del siglo XIX.

Hay dos aspectos de interés paradigmático, en cuanto a la manera en que se escribe la historia, en el texto de González. Primero, la narración no se enfoca en los procesos nacionales en un plano diacrónico extendido, sino que lo hace en un período de veinticuatro horas en un pueblo de las montañas de Puerto Rico. Segundo, la novela desarrolla varios núcleos narrativos indirectamente relacionados entre sí. Tercero, se emplean diversos recursos narrativos para poner de relieve las diferentes perspectivas sobre la invasión que tienen varios sectores sociales. De esta manera, el texto presenta el evento histórico como si fuera una recolección de diferentes testigos, con diferentes perspectivas. Además, la voz dominante se marginaliza, ya que los únicos miembros del reparto de personajes pueblerinos que repudian la invasión son representados como elementos conservadores extranjeros o de tendencias extranjerizantes.

En La llegada, González se interesa en una serie de personajes que viven en un pueblo de las montañas puertorriqueñas. Los procesos mentales de la gente son representados con el fluir de la consciencia, del estilo indirecto libre y del diálogo entre los personajes. La narración también representa las interacciones entre los miembros de diferentes grupos sociales y raciales. Los miedos y esperanzas de los personajes son sinécdoque de las perspectivas de distintos grupos raciales y sociales sobre la coyuntura histórica; en su totalidad, dichas representaciones comentan la variedad de voces que tenían una visión propia del hecho histórico. Por la misma multivocidad de la recreación del momento histórico, la novela crea un visión pluralista, democrática y, ante todo, contrahegemónica del proceso histórico.

La novela se organiza en quince capítulos cuya secuencia corresponde a una cronología paralela al arribo de las tropas anglonorteamericanas a Llano Verde. La disposición de los capítulos culmina con el rendimiento celebratorio del pueblo a cargo de los concejales del ayuntamiento. La estructura de la novela es fragmentaria y heterogénea, ya que los capítulos focalizan diferentes personajes, clases sociales y eventos, y cambian de tono y estilo narrativos. Como en una crónica, los hechos se presentan en orden cronológico sin visos de seguir un argumento, como si el texto fuera un mero registro de sucesos sin especificar el proceso histórico. ${ }^{7}$ Para González, esta representación pacífica revela una historia de la

\footnotetext{
${ }^{7}$ Hayden White discute la distinción entre "crónica" e "historia": "It is commonplace [...] that an historical discourse does not represent a perfect equivalent of the phenomenal field it purports to describe. [...] Here [...] we must confront the conventional [...] distinction between the 'mere' chronicles and the history properly so-called. Everyone grants that the historian must go beyond the serial organization of events to the determination of their coherency as a structure and assign different
} 
gente de Puerto Rico que no fue frustrada por la llegada de los Estados Unidos, sino que implicó una mejora en la vida de los oprimidos.

Comentaré, para continuar con esta elaboración, el título y el epígrafe de la novela, y la caracterización que González hace del contexto sociohistórico utilizando el cuadro de personajes.

Desde el título, La llegada: crónica con 'ficción', la novela nos presenta el tono irónico, autoconsciente y autorreflexivo, de este ejercicio historiográfico. Al usar la palabra "llegada" en vez de "invasión" González borra la connotación de víctima que recibe el país, en la interpretación independentista de la coyuntura nacional. Además, la yuxtaposición de las palabras "crónica" y "ficción" invoca el valor crítico que asume la obra ante la historiografía como género. El texto apunta hacia la reconsideración genérica de la ficción y la historia para cuestionar la autoridad de la manipulación del registro histórico sobre la ficcionalización de un hecho. En última instancia, la pregunta no debería ser qué porción de la narración es verdad, sino qué tipo de representación articula con más acuidad el contexto y la situación del periodo.

El epígrafe, del poeta nicaragüense Ernesto Cardenal, apunta hacia la indagación genérica, la cual se ocupa de la manera en que la historiografia propone un programa nacional, un "modelo" de sociedad y una noción de la "tradición" que benefician a una clase social.

El conde de Puñonrostro quiso silenciar a Herrera:

don Francisco Arias Dávila é Bobadilla Conde de Puñonrostro

del Consejo de Guerra de Vuestra Magestad, digo:

que Antonio de Herrera coronista de Vuestra Magestad

tiene escriptas, en lo que trata de Pedrarias Dávila mi abuelo

[...] se enmienden los pliegos que de esto tratan

antes que la Historia se publique [...]

Contesta Herrera:

NON DEBE EL CORONISTA DEJAR DE FACER SU OFICIO

El historiador no es un mero recopilador de datos. Su labor es organizar el registro histórico, omitir los datos descartables, crear jerarquías de datos y dar un aura de organicidad totalizante a la presentación de la historia, como si lo que existe en el presente fuera resultado directo del pasado y nos informara de un carácter y un destino nacionales. ${ }^{8}$ Dicha "ilusión

functional values to the individual events and the classes of events to which they appear to belong. This task is usually conceived, however, as that of 'finding' the story of stories that are supposed to lie embedded within the welter of facts reported in the record or the diachronic series of events as arranged in the chronicle.[...] What is involved here is a fashioning.[...] But this fashioning is a distortion of the whole factual field of which the discourse purports to be a representation - as in the case in all model-building" (111).

${ }^{8}$ Para Etienne Balibar este proceso es propio de la creación de un carácter nacional: "Such a representation clearly constitutes a retrospective illusion, but it also expresses constraining institutional realities. The illusion is twofold. It consists in believing that the generations which succeed one another over centuries on a reasonably stable territory, under a reasonably univocal designation, have handed down to each other an invariant substance. And it consists in believing that the process of 
retrospectiva" privilegia a una clase social que viene a ser la heredera del mando por mor de su dedicación eterna al beneficio de la nación.

Dentro del contexto de la obra de González descubrimos que esta crítica se dirige hacia la clase criolla puertorriqueña y a su componente historicista en el "discurso independentista tradicional". En La llegada el emplazamiento de la historiografía en cuestión toma la forma de la "crónica con "ficción"” para acoger a personajes representativos de sectores, cuyas voces y experiencias han sido omisiones notables, y para matizar la posición de las élites nacionales a fines del siglo XIX. Específicamente, la novela caracteriza de opresivo al régimen colonial español y a su estructura administrativa local, compuesta principalmente por españoles y conservadores, y apoyada por los criollos de tendencia liberal. El texto traza, además, las fronteras que separan a las élites puertorriqueñas de las clases populares y recrea la estructura administrativa y económica que mantiene sometidos a la mayoría de los personajes. La ficcionalización del momento histórico nos presenta un cuadro social y económico que difiere de la visión idealizante y utópica que difunde, según González, el discurso independentista tradicional. ${ }^{?}$

El primer capítulo de la novela nos narra la retirada desesperada de varios elementos del ejército español y el arribo pacífico y hasta celebratorio del ejército estadounidense. Estos dos acontecimientos marcan el periodo de transición que se impone por los cambios geopolíticos. El narrador remarca el desprecio de los "hijos del país" hacia los españoles, pues "de aquellas avanzadas había salido una y otra vez el grito que les traía ardiendo las orejas [a los españoles]: ‘Cachacos hijos de la gran puta, al fin les llegó su hora!'” (11). El desmoronamiento del poder colonial español permite y promueve las expresiones de hostilidad y, a la vez, desenmascara la represión de la que eran víctimas los puertorriqueños.

Dicha dinámica se reproduce mediante una escena en la que cuatro de los soldados españoles llegan a una choza para exigirles agua a los habitantes. La humilde vivienda y la precaria salud de éstos son muestra de lo inhumano y opresivo del régimen colonial saliente, encarnado, en esta escena, por el sector castrense. Luego de recibir el agua "el hombre fijó en la campesina sus ojos vidriados por la fiebre y, arrojándole a los pies la dita vacía, gritó con la voz ronca, como un reto:- ¡Viva España!"(13). Al retirarse los soldados, el labriego "quebró el rústico envase sobre la tierra dura. [...] Después [...] sin cruzar palabra, [los jíbaros] regresaron al bohío" (14). La narración caracteriza la victimización del campesinado pobre y el desprecio generalizado hacia los españoles.

La llegada de las tropas estadounidenses contrasta marcadamente con la retirada de los españoles por la prisa de éstos y la calma de aquéllos, y por el estilo de la interacción con los pobladores de la región durante la movilización. Por su parte, la actitud de las tropas angloamericanas no es hostil en forma, sino relajada y hasta juguetona. Los niños de la

development from which we select aspects retrospectively, so as to see ourselves as the culmination of that process, was the only possible, that is, represented a destiny" (86).

${ }^{9}$ Según González, en "El país": "La idealización —-vale decir la tergiversación- del pasado histórico ha sido uno de los rasgos típicos de esa ideología. Pedro Albizu Campos fue [...] el portavoz más coherente y consecuente de esa ideología conservadora. Conservadora en su contenido, pero, en el caso de Albizu, radical en su forma, porque Albizu dio voz especialmente al sector más desesperado [...] de esa clase. Esa desesperación histórica [...] fue la que obligó a Albizu a tergiversar la verdad refiriéndose al régimen español en Puerto Rico como 'la vieja felicidad colectiva"' (17-18). 
región remedan la marcha militar, y mantienen un tono celebratorio y admirativo. La narración se enfoca en la curiosidad de "la jibarada" ante unos "extraños adminículos que algunos de los soldados traían encajados en las cintas de sus sombreros de fieltro endurecido. Porque nadie en Machucales había visto hasta entonces un cepillo de dientes" (14-15). A pesar de que los españoles opusieron una resistencia militar a las tropas estadounidenses, gran parte de los colonizados de la región les dieron una recepción pacífica. $^{10}$

Desde sus principios, el texto caracteriza el advenimiento de un nuevo poder colonial a Puerto Rico como un suceso positivo y sugeridor de un cambio hacia una sociedad más moderna. Esta visión anuncia el contraste que habrá de repetirse en otros momentos de la novela, en que las actitudes receptivas del antiguo esclavo Quintín Correa y de su esposa, del sindicalista Catalino Romero y de los criollos liberales, van a oponerse a las posturas antagonizantes del alcalde español y del sacerdote del pueblo. Esta división apunta a los beneficios que disfrutaban los españoles y conservadores bajo España y recuerda los sufrimientos de las clases populares. Los criollos liberales, dado sus proyectos políticos y económicos, asumen que el cambio de poder les permitirá desplazar a las élites españolas como la clase de mayor hegemonía dentro del nuevo sistema colonial.

Los personajes de la novela que encarnan el proyecto político imperial en Llano Verde son don Sebastián Camuñas, alcalde del pueblo, el padre Antonio y un soldado español herido en una refriega. De los tres personajes, el de más interés para nuestro estudio es el primero, por ser quien domina la estructura administrativa local y quien personifica el estilo de dominación colonial que el texto dramatiza. En la novela, el alcalde no disfruta del apoyo popular mas asume su posición con autoridad y sin hacer mayores esfuerzos por seguir un estilo de gobierno democrático. Su poder ejecutivo proviene de la estructura colonial, apoyado por los aparatos ideológicos y represivos de dicho sistema. ${ }^{11}$

La primera vez que vemos al alcalde es en el quinto capítulo durante una reunión del ayuntamiento, cuerpo que preside por virtud de su cargo, el cual ha sido convocado para decidir la acción a tomar dada la inminente llegada del ejército estadounidense. Los miembros del concejo están divididos por líneas ideológicas, aunque la caballerosidad no permita que las afiliaciones políticas queden en evidencia. El humor afable alegre de los

\footnotetext{
${ }^{10}$ La recepción pasiva de las tropas estadounidenses fue una realidad en muchos pueblos de la isla. En La llegada este elemento patentiza la adhesión que muchos puertorriqueños sentían hacia los estadounidenses. Otro factor de importancia es que las tropas estadounidenses superaban numéricamente, en proporción de tres a uno, a las españolas, y que la mayor parte del contingente español estaba agrupado en San Juan, mientras que los angloamericanos desembarcaron en Guánica, al sur de la isla. Hubo combate esporádico con victorias fáciles para los invasores. Debe recordarse que muchos puertorriqueños sirvieron de voluntarios para los invasores y que muchos formaron sus propias milicias para atacar al ejército de la corona, a los conservadores en diferentes pueblos, y a los terratenientes de ascendencia o proveniencia europea (Picó 186-187).

"Tomamos este término de Louis Althusser y a la misma vez lo asociamos al concepto de lo económico corporativo que utiliza Antonio Gramsci. La organización en el siglo diecinueve imponía una participación en el régimen colonial a la que se "sometían" los subalternos y dentro de la cual dominaba el sector económico corporativo (conservadores y liberales, españoles y criollos). Los principios ideológicos coloniales se materializaban de manera concreta en lo "vivido".
} 
concejales liberales, el doctor Martínez Coss y el abogado Juan José Benítez, hace que el alcalde pierda la paciencia. Ante la llegada vemos que el alcalde se muestra apremiado pues el cambio de mando no sólo disolverá su posición de poder, sino que pondrá en juego su mismo bienestar económico y físico. Luego de varios años de participación en la explotación de los puertorriqueños pobres y la represión de los liberales y separatistas, sería de esperar que se tomaran represalias en su contra. Su papel en la entrega del pueblo tiene que ser sabiamente negociado para preservar algún poder que le asegure su protección.

En el séptimo capítulo, Sebastián Camuñas se persona en lo que González llama "la zona tricolor", "donde blancos, negros y mulatos habían aprendido a convivir bajo el común denominador de la pobreza" (61), para visitar a Joaquín Cepeda, antiguo informante suyo durante la época de los compontes. El alcalde viene en busca de información sobre su seguridad personal en un momento de alto riesgo. Al llegar a la casa de su antiguo informante, se encuentra con Quintín Cepeda, bedel del ayuntamiento y antiguo esclavo, al cual le habían ordenado que velara la entrada al pueblo en caso de que el ejército estadounidense llegara a esas horas.

Esta secuencia patentiza la estructura del espacio social del pueblo que, como aparato ideológico del estado, reproduce la ideología colonial. La pirámide del poder tiene como base los elementos más pobres, de distintos grupos raciales y oficios, mientras que las clases profesionales y los españoles ocupan los estratos superiores. De tal forma, la cartografía del pueblo otorga un carácter orgánico a la estratificación del poder político y económico. ${ }^{12} \mathrm{~A}$ la vez que permite la vigilancia de los elementos populares y crea desconfianza entre las capas inferiores y superiores, otorga cierta cohesión dentro de los diferentes fragmentos socioeconómicos. En el caso específico del pueblo ficticio, se simboliza la unión entre liberales y conservadores ante las clases populares. Este factor permite la creación de una posición de subalternidad para la zona tricolor y evita la consolidación de nexos solidarios entre los fragmentos de las clases superiores, en este caso los liberales, y las clases inferiores. ${ }^{13}$

Otro aspecto de importancia en este capítulo es la articulación del poder represivo dentro de la colonia. Se alude a la función de Joaquín Cepeda en una iniciativa represiva llamada "los compontes" durante lo que llegó a llamarse en la historiografia puertorriqueña "El año terrible del 87" (Pedreira, El año terrible). El empleo de informantes de las clases populares incapacita el potencial de rebelión ante las estructuras del poder político y subraya, ante todo, la fragilidad del poder colonial, la desconfianza en el pueblo y la necesidad de emplear la fuerza para lograr la participación en las empresas coloniales.

\footnotetext{
${ }^{12}$ Según Michel de Certeau, "[on hand]there is a differentiation and redistribution of the parts and functions of the city, as a result of inversions, displacements, accumulations, etc. [...]; on the other there is a rejection of everything that is not capable of being dealt with in this way and so constitutes the 'waste products' of a functionalist administration (abnormality, deviance, illness, death, etc.)" (155).

${ }^{13}$ Lo "económico corporativo" impone y mantiene su hegemonía, según Gramsci, evitando la creación de nexos solidarios entre las clases populares y los fragmentos de otras clases: "All history from 1815 onwards shows the efforts of the traditional classes to prevent the formation of a collective will of this kind, and to maintain 'economic corporate' power in an international system of passive equilibrium" (Gramsci 132).
} 
En la novela, Sebastián Camuñas desdeña a los puertorriqueños, los percibe como inferiores a los suyos y rechaza la animosidad frente a los españoles como "un ruin resentimiento". Para el alcalde, los "hijos del país, aun los que no descienden de africanos, no heredaron la nobleza de carácter que España prodigó durante cuatro siglos en estas tierras" (62). Menospreciay desdeña a los puertorriqueños, especialmente alos descendientes de africanos, y, por lo mismo, ve al régimen colonial como la forma de gobierno ideal para Puerto Rico.

En general, vemos que la novela nos presenta un sector conservador que impone una estructura social opresiva y un sistema de gobierno represivo. Dichas formas tienen como propósito dominar la población insular, mantener a los sectores populares subyugados y explotados, y controlar, por medio de concesiones estratégicas, a los sectores criollos, fragmentos de las clases dirigentes del país. Además, el personaje del alcalde manifiesta una ideología de superioridad española ante los "hijos del país". Esta representación de las clases dirigentes de la isla, a la altura de 1898, desdice con fuerza la idealización del régimen colonial español y el "discurso independentista tradicional".

Uno de los puntos de articulación significativos de la novela es el sector liberal, representado por el abogado Juan José Benítez y el doctor Ramón Martínez Coss, y sus respectivas familias. El ejercicio historicista se complica al incluir referencias a las estrategias políticas de este sector dentro y, sobre todo, fuera de la isla. La novela recuerda la manera en que los autonomistas se distanciaron de los separatisfas, para no ser víctimas de las persecuciones políticas, adoptando una actitud reformista. ${ }^{14}$ Este proyecto político se recuerda a través de discusiones en el seno de la familia Benítez so pretexto de charla informal entre el abogado y su esposa. Amén de estas discusiones de carácter didáctico y paternalista, vemos cómo la posición estratégica de los liberales se transforma para acoger con beneplácito al nuevo mando en Llano Verde.

En el segundo capítulo, la esposa española de Benítez le expresa su preocupación de que será una extranjera, luego del cambio de poder. Para el abogado, el cambio es inevitable pues el dominio español en ultramar se estaba debilitando debido a la prolongada guerra emancipadora en Cuba, la inestabilidad política interna en España y el interés creciente de los Estados Unidos en controlar su periferia. ${ }^{15}$

La novela crea una visión bipolar de la dinámica política en Puerto Rico al proponer el contrapunteo conservador español/liberal criollo. Lejos de ser una simplificación de las interacciones entre poderosos insulares, dicha representación se ofrece como sinécdoque de

\footnotetext{
${ }^{14}$ La Constitución Autonómica, otorgada en 1897, había sido la concesión más importante en la lucha española por mantener a Puerto Rico. La guerra de liberación cubana era fuente de gran preocupación en España y en el mismo Puerto Rico, aunque las intentonas de levantamiento en Puerto Rico habían sido aplacadas con celeridad. En España regía el Partido Liberal Monárquico, el cual promovía, bajo el mando del primer ministro Práxedes Sagasta, una postura reformista y conciliatoria, especialmente con Puerto Rico.

${ }^{15}$ Es de reconocer que era de suma importancia para los Estados Unidos controlar las Américas. Con respecto a la agencia de dicho país en los trastornos geopolíticos de Latinoamérica y, en especial, Puerto Rico, ver Barbusse, Cruz Monclova, Guerra y Sánchez, le Feber, Rivero, y Estades Font.
} 
unas transacciones entre poderes imperiales y de modernización. ${ }^{16}$ La reestructuración de la maquinaria de mercados globales no puede sino afectar de manera significativa la estructura interna puertorriqueña. Ante ésta, la novela traza la trayectoria estratégica de los liberales, los cuales adoptan una posición para beneficio de su propia clase social. Esta plasmación contrasta con la idealización de los criollos que González critica en "El país de cuatro pisos" y propone una visión histórica que hermana a conservadores y liberales como miembros de la clase dirigente insular. ${ }^{17}$

Estas conexiones entre conservadores y liberales tienen como propósito simbolizar una dinámica que ocupa a los dirigentes en Puerto Rico. El poder político, dada la hegemonía en España del Partido Monárquico Liberal y el primer ministro Práxedes Sagasta, se había repartido entre liberales y conservadores, pero no había alcanzado a la base de la sociedad. Por lo tanto, los criollos, cuyas adhesiones ideológicas se representan como liberales, estaban lejos de ser la personificación del "pueblo" puertorriqueño, por disfrutar de los beneficios del poder sin los sufrimientos de los demás colonizados, es decir, los negros, mulatos y blancos pobres. Muy a pesar de su apego al liberalismo, ponían sus intereses antes que los intereses de los verdaderamente oprimidos. El texto pone de relieve la imposibilidad de ver al régimen colonial español de manera "honesta" si sólo se considera como representativa la visión de los criollos, hacendados o profesionales.

Ante esta parcelación del marco del poder, quedan por discutir las esferas extrahegemónicas, que en la novela se llama "la zona tricolor", y que apunta a lo que Bhabha llamaría la "perspectiva de la minoría". Nos centraremos en los personajes de Catalino Romero, obrero sindicalista, y Quintín Correa, un antiguo esclavo y bedel del ayuntamiento.

El primero de estos personajes, Catalino Romero, aparece en la novela en el sexto capítulo, cuando la esposa de Quintín Romero viene a pedirle que construya el féretro de Joaquín Cepeda, el informante del alcalde que antes mencionamos. El carpintero accede y la conversación manifiesta la unión entre los pobres del pueblo, como diría Petronila, la esposa de Quintín, "los pobres siempre encontramos la manera de ayudarnos"(93). Además de estas conexiones solidarias entre los oprimidos y marginados, este espacio en el texto muestra las afiliaciones ideológicas de los trabajadores y su perspectiva ante la invasión y el cambio de gobierno.

Aquella noche Catalino Romero había estado despierto esperando la posible llegada a su casa del líder sindical Santiago Iglesias Pantín, ${ }^{18}$ quien se había escapado de su prisión, gracias al bombardeo estadounidense. Romero estaba comprometido con el sindicalismo

\footnotetext{
16 "Modernization can be directly linked to the many different 'objective' processes of structural change that have been associated with the ability of capitalism to develop and survive, to reproduce successfully its fundamental social relations of production and distinctive divisions of labour despite endogenous tendencies towards debilitating crisis" (Soja 26-27).

${ }^{17}$ Según González, "Es perfectamente demostrable, porque está perfectamente documentado, que la clase propietaria puertorriqueña acogió la invasión norteamericana, en el momento en que se produjo, con los brazos abiertos.... porque vieron en ella el preludio de la anexión de Puerto Rico a la nación más rica y poderosa - y más 'democrática', no hay que olvidarlo- del planeta" ("El país" 30).

${ }^{18}$ Sindicalista español que ocupó un lugar central en la lucha por los derechos de los trabajadores en Puerto Rico, miembro fundador de la Federación Libre de Trabajadores, luego afiliada al American Federation of Labor.
} 
y con los intereses de los trabajadores, a pesar de las persecuciones que sufría el movimiento bajo el régimen español. Por estas circunstancias, la invasión anunciaba un cambio significativo porque, como él expresa, "Las cosas en las que nosotros creemos no son delito en los Estados Unidos. Allá el movimiento obrero es legal, hay derecho a huelga, hay libertad de expresión y de reunión..."(91). Al considerar esta perspectiva parece innegable que, más que un acto violento e impositivo, el cambio de poder colonial implicaba una mejoría en la calidad de vida de los trabajadores.

Más todavía, como expresara González en "El país de cuatro pisos", "La clase trabajadora puertorriqueña [...] acogió favorablemente la invasión norteamericana. [...] En la llegada de los norteamericanos a Puerto Rico los trabajadores vieron la oportunidad de un ajuste de cuentas con la clase propietaria en todos los terrenos" (33). Romero ve claramente su posición de explotado bajo los propietarios europeos, y apunta que "los que tienen razones para estar con el alma en un hilo son los cachacos de la altura. Y los mallorquines, que no son menos explotadores de los pobres jibaros" (91). Aquí vemos que el texto, empleando la "acumulación semántica contextual"(Román 79), significa lo que fue la llegada para los sectores populares, explica cómo esta perspectiva contradice la del independentismo tradicional y patentiza las divisiones de clase en la isla durante el siglo XIX.

El segundo personaje que importa discutir es Quintín Correa, cuya posición de subalterno ejemplifica el racismo inherente al sistema colonial español y recuerda la institución de la esclavitud. Durante la novela vemos a Quintín como una presencia constante y silente, sirviendo a los concejales durante las reuniones del ayuntamiento, atendiendo a Joaquín Cepeda y llevando a cabo los encargos del alcalde. No es hasta el undécimo capítulo que Quintín aparece como centro de un núcleo narrativo. Durante éste, Quintín, que ha sido enviado a estar en vela de la llegada de las tropas invasoras, rememora sus años de esclavo en la isla, sus labores en el campo, su relación con su madre africana, la represión cultural, religiosa y lingüística de lo africano, las maneras en que se resistía dicha dominación y su puesto de subalterno de los blancos aún después de la abolición de la esclavitud. La imagen de Quintín "crea una imagen de diferencia cultural y política entre las poblaciones blancas y negras de la isla" (Irizarry, "El valor" 6).

$\mathrm{Al}$ recordar a su madre, la narración, por medio del estilo indirecto libre, traza una identidad nacional y una visión de sus orígenes, muy distinta a la transmitida por el discurso independentista tradicional criollizante:

su madre no era puertorriqueña sino africana. Ella misma se lo había comentado en más de una ocasión; pero todo lo que eso significaba [...] era que ella había nacido en África y la trajeron a Puerto Rico antes de cumplir los doce años [...] de ahi a ser africana y no puertorriqueña había un buen trecho (107-108).

Más allá de su genealogía, su historia como elemento integral de los medios de producción y de fuente de plusvalía, para el beneficio de españoles y criollos pudientes, reclama un reconocimiento dentro de la identidad nacional. Quintín recuerda que "crecer [...] fue trabajar" y que "los años en que culminó su vigor físico fueron los que conocieron el abuso más brutal de su energía" (115). Sin embargo, su pasado de explotación esclavista 
pasó a ser su explotación asalariada, luego de la abolición de la esclavitud. Su experiencia y su consciencia le fuerzan a reconocer que "¿qué seguía siendo él, a fin de cuentas, a los ojos de quienes en realidad eran los dueños de la vida en Llano Verde, sino 'el negro Quintín' de siempre" (117).

Quintín evaluaba la llegada de los invasores de esta manera: "Peores que los españoles de seguro no serían: en su propio país tenían una república, y habían abolido la esclavitud diez años antes de que lo hiciera España" (119). El texto caracteriza a un ser consciente de los problemas inherentes al régimen español y de su posición dentro de esta sociedad. A la vez, sugiere que sería anacrónico que la descendencia africana en la isla aceptara las propuestas separatistas y nacionalistas que nieguen su pasado "de esclavitud, importación, indoctrinación y explotación de africanos, de epidemias en barracones, de latigazos y cepos ... [de] un periodo bochornoso para su imaginario nacional" (Irizarry, "El valor" 6). En "El país", González ya había expresado el rechazo generalizado de los puertorriqueños negros a la ideología independentista.

La llegada dramatiza la "tergiversación de lahistoria" del "independentismo tradicional" que González apunta en "El país", que obvia la experiencia del puertorriqueño de origen africano, para poder generar unas propuestas de nación que borren el racismo inherente al sistema colonial español y la explotación de un sector significativo de la sociedad insular, a manos de una minoría criolla y europea. ${ }^{19}$. Además, esta falsificación de este discurso provoca una reconsideración de la dinámica nacional que incluya de manera integral una discusión sobre la importancia de la raza y la etnicidad en la creación de las jerarquías de valores y comunidades dentro de la nación.

La novela termina con la ceremonia de entrega del pueblo protagonizada por los concejales y el alcalde, contando con la asistencia de un buen número de los pobladores de Llano Verde. Dicha escena tiene un tono festivo que incluye el despliegue de la bandera estadounidense, a manos de la familia del doctor liberal Coss, y el ofrecimiento de su hogar como hospedaje para el coronel McKintosh, por parte del abogado Juan José Benítez. El único evento que lleva un tono triste es el paso del féretro de Joaquín Cepeda como metáfora de la muerte del sistema represivo y hostigador español.

A la luz de las propuestas de González sobre el discurso nacionalista puertorriqueño, podemos ver la articulación textual y la oposición de los grupos de personajes como una falsificación del discurso independentista tradicional. El rechazo primordial de la visión del siglo XIX como "la vieja felicidad colectiva" se manifiesta en la prepotencia del alcalde español y el desprecio de éste hacia los puertorriqueños, en la posición acomodaticia de los liberales criollos ante el nuevo poder colonial, y en el desprecio que los sectores populares tenían hacia el régimen colonial saliente.

Al mismo tiempo, La llegada es un texto historicista que adjudica un valor particular a un momento histórico en tanto que lo hace revelador de unas dinámicas sociales específicas. La relación entre españoles y criollos traza la reorganización del poder local como consecuencia de la reestructuración política en España, la crisis del modelo imperial

\footnotetext{
${ }^{19}$ Para González, "lo que un puertorriqueño negro [...] [entiende] por 'volver a los tiempos de España', es volver a una sociedad en la que el sector blanco y propietario de la población siempre oprimió y despreció al sector no-blanco y no-propietario" (35).
} 
español, el surgimiento de un nuevo poder hegemónico y la reestructuración de los mercados globales. La relación entre la clase dominante y la clase trabajadora ejemplifica una relación de explotación, mantenida por un sistema represivo y articulada por medio de una estructuración del espacio social, vista en Llano Verde en la llamada "zona tricolor". Las relaciones entre razas se problematizan al recordar la esclavitud que explotó de una manera específica a los negros en Puerto Rico y que tuvo como descendiente una fragmentación social que continuó aun después de la emancipación de los esclavos.

Es de importancia considerar el texto como diseminador de unos valores particulares y de un programa nacional de cierto tipo. Ante todo, podemos entender que la novela sugiere una identificación entre los miembros de las clases populares. Al representar a "la zona tricolor", se crea un espacio en que "blancos, negros y mulatos habían aprendido a convivir bajo el común denominador de la pobreza" (61). Dicho espacio se propone como el gérmen donde los sentimientos más nobles existen y donde se reproduce, como resultado de la pobreza, una ideología de la solidaridad entre pobres. ${ }^{20}$ Ejemplo de esto es el aforismo de Petronila "los pobres siempre encontramos la manera de ayudarnos" (93). Podemos encontrar en la acumulación semántica una sociedad de subalternos, dirigida por un puñado de dominadores. Ante esta imagen la teleología de la emancipación de la mayoría aparece como la opción imperante, que González explicita en "El país de cuatro pisos":

"una democracia industrial gobernada por los trabajadores" [...] que, apoyándose en la
tradición cultural de las masas populares, redescubra y rescate la caribeñidad esencial de
nuestra identidad colectiva y comprenda de una vez por todas que el destino natural de
Puerto Rico es el mismo de todos los demás pueblos, insulares y continentales, del Caribe
(40).

Discutir el 98 se convierte en una manera de reconsiderar los gestos hegemónicos de las historias puertorriqueñas, latinoamericanas, hispanas, americanas. La llegada intenta falsificar lo hispanófilo, criollista y europeizante de la historia de Puerto Rico, enfocándose en la manera en que se desplomaba la estructura colonial española y se implantaba una crisis de proporciones hemisféricas y, asaz, globales. Por medio de la dramatización de las diferencias sociales, el texto adquiere un matiz desmitificador de una "vieja felicidad colectiva" y de unas genealogías del poder que sobreviven en nuestros días. Más allá del valor de La llegada en Puerto Rico, sugerimos que este proceso de falsificación continúe en las literaturas y críticas culturales latinoamericanas para procrear un imaginario de la subalternidad con sus propias consecuencias reales.

A modo de coda, quisiéramos sugerir que la escritura de este texto en 1979, en México, puede considerarse como parte de un debate prolongado entre una visión criollista, patriarcal y europeizante de la historia, y una visión dialéctico-materialista (Rodríguez Castro). Podríamos considerar las propuestas socialistas del escritor como parte de una sugerencia utópica de la creación de una confederación antillana que se acople, con toda la

\footnotetext{
${ }^{20}$ Podemos considerar la zona tricolor como un "lugar heterogéneo" que contiene la materia para la transformación social: "These heterogeneous spaces of sites and relations-Foucault's heterotopiasare constituted in every society but take quite varied forms and change over time, as 'history unfolds' in its adherent spatiality" (Soja 17).
} 
soberanía de un estado independiente, a un orden socialista. En ese "31 de diciembre del 1979" no se sospechaba el desmoronamiento del bloque soviético y la crisis del socialismo a nivel global. Tampoco se sospechaba el surgimiento de la reestructuración masiva de los mercados que ha dado por llamarse el Nuevo Orden Mundial.

Sin embargo de estas interpretaciones regidas por el contexto de la escritura, podríamos considerar la manera en que el texto de La llegada se ha añejado, adquiriendo unas significancias inusitadas. Consideremos, de manera breve y sugerente, cómo los fenómenos de la globalización y la transnacionalización han tomado por sorpresa al mundo provocando una reestructuración masiva de las relaciones de poder a nivel geopolítico. A la vez, estos cambios han deshecho la política de la inmovilidad, bajo la cual los Estados Unidos mantuvieron a Puerto Rico durante la década de los setenta (Gautier Mayoral), y produce la propuesta del Proyecto Young que se perfila como una posible alteración de la relación entre estos países, a la vez que se reajusta el papel de la isla en el Caribe (García Passalacqua). El posicionamiento estratégico de las élites puertorriqueñas, dividas entre estadoistas y estadolibristas, emula, por sus afiliaciones y deseos de autonomía, a aquéllas conservadoras y liberales del siglo pasado. Sin exagerar las similaridades, y sin sugerir genealogías, podemos tomar la ironía de la historia que se repite como estructura inherente a los procesos geopolíticos amplios y a los efectos de crisis y reorganización que repercuten a nivel regional, nacional y de comunidades como Llano Verde.

\section{OBRAS CITADAS}

Althusser, Louis. "Ideology and Ideological State Apparatuses". Lenin and Philosophy. New York: Monthly Review, 1971.

Balibar, Etienne. "The Nation Form: History and Ideology". Race, Nation, Class: Ambiguous Identities. Chris Turner, trad. 1991. Londres: Verso, 1992. 86-106.

Barbusse, Edward. The United States in Puerto Rico: 1898-1900. Chapel Hill: University of California Press, 1966.

Bhabha, Homi. The Location of Culture. 1994. Londres: Routledge, 1995.

Certeau, Michel de. "Walking in the City". The Practive of Everyday Life. Berkeley: University of California Press, 1984.

Clifford, James. "Identity in Mashpee". The Predicament of Culture. Cambridge: Harvard University Press, 1988. 277-346.

Cruz Monclova, Lidio. Historia de Puerto Rico en el siglo XIX. Río Piedras: Universitaria, 1957-1964. 3 vols.

Estades Font, María E. La presencia militar de Estados Unidos en Puerto Rico 1898-1910: Intereses estratégicos y dominación colonial. Río Piedras: Huracán, 1988.

García Passalacqua, Juan Manuel. “Ariadne's Thread: Puerto Rican Nationality in the Caribbean". Ethnicity, Race, and Nationality in the Caribbean. Juan Manuel Carrión, ed. Río Piedras: Institute of Caribbean Studies, 1997.

Gautier Mayoral, Carmen, y otros. Puerto Rico en las Relaciones Internacionales del Caribe. Río Piedras: Huracán, 1990.

González, José Luis. "El país de cuatro pisos: Notas para una definición de la cultura puertorriqueña". "El país de cuatro pisos" y otros ensayos. 7a edición. Río Piedras: Huracán, 1989. 11-42. 
La llegada: Crónica con ficción. Río Piedras, Huracán, 1980.

Gramsci, Antonio. Selections from the Prison Notebooks. Quintin Hoare y Geoffrey Nowell Smith, ed. y trad. New York: International Publishers, 1971.

Guerra y Sánchez, Ramiro. La expansión territorial de Estados Unidos a expensas de España y los países hispanoamericanos. La Habana: n.p., 1964.

Irizarry Díaz, Guillermo B. "The Image of Puerto Rico in José Luis González's National Triad". Tesis Doctoral de la Universidad de Texas en Austin, 1996.

"El valor semántico de la historia en La llegada de José Luis González". Conf. dictada en "1898-1998: Nation, Culture, and Identity", Florida International University, Miami, 23-25 de octubre de 1997.

Le Feber, Walter. The New Empire: an Interpretation of American Expansion: 1860-1898.

Pedreira, Antonio S. El año terrible de 87. San Juan: Biblioteca de Autores Puertorriqueños, 1946.

Insularismo: ensayos de interpretación puertorriqueña. 3a edición. San Juan: Biblioteca de autores puertorriqueños, 1946.

El año terrible del 87. San Juan: Biblioteca de autores puertorriqueños, 1935.

Picó, Fernando. Historia general de Puerto Rico. 2a edición. Río Piedras: Huracán, 1986.

Rivero, Ángel. Crónica de la Guerra Hispanoamericana en Puerto Rico. Madrid: n.p., 1922.

Rodríguez Castro, María Elena. "Las casas del porvenir: Nación y narración en el ensayo puertorriqueño". Revista Iberoamericana 59 (1993): 44-53.

Román Riefkohl, Raúl A. "Crónica de una llegada anunciada: La llegada de José Luis González". Caravelle 43(1984): 69-80.

Soja, Edward J. "History: Geography: Modernity". Postmodern Geographies. Londres: Verso, 1989. 10-42.

White, Hayden. "Historicism, History, and the Figurative Imagination". Tropics of Discourse. Baltimore: Johns Hopkins, 1992. 
